\title{
Neonatal Transfer Situation Following Implementation of a Perinatal Network: An Analysis in Douala, Cameroon
}

\author{
Daniele Kedy Koum ${ }^{1,2 *}$, Diomede Noukeu Njinkui ${ }^{3,4}$, Monique Carole Magnibou ${ }^{1}$, \\ Loick Pradel Kojom Foko ${ }^{5}$, Charlotte Eposse ${ }^{1}$, Rhita Mbono', \\ Patricia Epée Eboumbou1, Calixte Ida Penda ${ }^{1,6}$
}

\author{
${ }^{1}$ Department of Clinical Science, Faculty of Medicine and Pharmaceutical Sciences, The University of Douala, Douala, Cameroon \\ ${ }^{2}$ Department of Pediatrics, Deido District Hospital, Douala, Cameroon \\ ${ }^{3}$ Department of Pediatrics, Douala Gyneco-Obstetrics and Pediatrics Hospital, Douala, Cameroon \\ ${ }^{4}$ Faculty of Medicine and Pharmaceutical Sciences, University of Dschang, Dschang, Cameroon \\ ${ }^{5}$ Department of Animal Organisms, Faculty of Science, The University of Douala, Douala, Cameroon \\ ${ }^{6}$ Department of Pediatrics, Douala General Hospital, Douala, Cameroon \\ Email: *dckedykoum@yahoo.fr
}

How to cite this paper: Koum, D.K., Njinkui, D.N., Magnibou, M.C., Foko, L.P.K., Eposse, C., Mbono, R., Eboumbou, P.E. and Penda, C.I. (2022) Neonatal Transfer Situation Following Implementation of a Perinatal Network: An Analysis in Douala, Cameroon. Open Journal of Pediatrics, 12, 148 161.

https://doi.org/10.4236/ojped.2022.121016

Received: December 30, 2021

Accepted: February 27, 2022

Published: March 2, 2022

Copyright $\odot 2022$ by author(s) and Scientific Research Publishing Inc. This work is licensed under the Creative Commons Attribution International License (CC BY 4.0).

http://creativecommons.org/licenses/by/4.0/ (c) (i) Open Access

\begin{abstract}
Background: Postnatal transfer (PT) is interhospital transport of care-needing newborns. In 2016, a perinatal network was implemented to facilitate PT in the town of Douala, Cameroon. The network was supposed to improve PTrelated care standards. This study aimed at determining characteristics of PT five years following the implementation of this network. Methods: A crosssectional study was carried out from February to May 2021 at neonatology wards of six hospitals in Douala. Medical records of newborns transferred to the hospitals were scrutinized to document their characteristics. Parents were contacted to obtain information on PT route and itinerary. Data were analyzed using Epi Info software and summarized as percentages, mean and odds ratio. Results: In total, 234 of the 1159 newborns admitted were transferred, giving a PT prevalence of $20.2 \%$ (95\% CI $17.9 \%$ - 22.6\%). Male-to-female ratio of the transferred newborns was 1.3 . Neonatal infection (26.5\%), prematurity (23.5\%) and respiratory distress (15.4\%) were the main reasons for transfer. Only $3 \%$ of the PT was medicalized while only $2 \%$ of the newborns were transferred through perinatal network. On admission, hypothermia and respiratory distress were found in $31 \%$ and $35 \%$ of the newborns, respectively. The mortality rate among babies was $20 \%$ and these had a two-fold risk of dying (95\% CI 1.58 - 3.44, $p<0.0001$ ). Conclusion: PT and the perinatal network are lowly organized and implemented in Douala. Sensitization of medical staff on in utero transfer, creating center for coordination of the
\end{abstract}


network, and implementation of neonatal transport system could improve the quality of PT.

\section{Keywords}

Postnatal Transfer, Perinatal Network, Characterization, Douala

\section{Introduction}

According to the World Health Organization (WHO), neonatal period goes from birth to $28^{\text {th }}$ day of life [1]. Postnatal transfer (PT) is greatly helpful for optimal management of newborns requiring to be transferred to health facilities with better quality healthcare services [2] [3]. Transfer relies on a gradation of care services and the main reasons for PT include prematurity, neonatal infections and surgical pathologies [3] [4]. Again, prematurity, neonatal infection and asphyxia account for the bulk of mortality cases in transferred babies, and are involved in $80 \%$ of neonatal deaths worldwide [5] [6].

In 2006, French Government released a circular on principles guiding the implementation of perinatal networks [7]. In Canada, ambulances allow newborns to be transported from local emergency medical services to intensive care units [8]. In 2019, prevalence of PT was $20 \%$ in Japan with perinatal network and medicalized transport used in $62 \%$ and 92 of the transfers, respectively [9]. In France, $20 \%$ of pre-term births were reported in health facilities (HF) with both no neonatology wards and requirement for PT [10].

In developing countries, PT patterns are contrasted. A study conducted in Tunisia reported prevalence of $6 \%$, medicalized transport in $47 \%$ and mortality of $8 \%$ [11]. In Senegal, PT was performed using ambulances in $30 \%$ of the transferred newborns and mortality rate of $22 \%$ was found [12]. In The Democratic Republic of Congo, $13 \%$ of newborns were transported, among them $92 \%$ were transported through public transport means [13].

In 2016, it was reported that $53 \%$ of newborns underwent PT and $20 \%$ of them were deceased, in the town of Yaoundé, Cameroon [14]. In December 2016, a perinatal network was implemented in Yaoundé and Douala to improve PT conditions [15]. With the final aim to improve PT quality and perinatal network, we conducted a study to identify bottlenecks of PT and determine mortality risk of transferred newborns in the town of Douala.

\section{Methods}

\subsection{Study Design and Sites}

From $1^{\text {st }}$ February to $31^{\text {st }}$ May 2021, a cross-sectional study was conducted at neonatology wards of six Government reference HF in Douala, Littoral Region, Cameroon. Health system in the country is pyramidal and neonatology wards of various standards are included [16]. Reference hospitals included are described 
as follows:

- Douala General Hospital (DGH) which is first category hospital endowed with neonatology unit offering resuscitation and intensive cares with 15 baby incubators, 6 cradles and 6 pediatricians;

- Douala Gyneco-Obstetrics and Pediatrics hospital (DGOPH) is also a first category health facility whose neonatology unit has 12 incubators and 10 cradles with a staff composed of four pediatricians and one neonatologist;

- Douala Laquintinie hospital (DLH) is a second category hospital with 8 baby incubators, 24 cradles and 4 pediatricians.

These three HF receive most of transferred newborns in Douala as they have the best and well-equipped maternities and neonatology services allowing for management of newborns in critical state.

Three fourth category District hospitals with facilities to manage pathologies and disorders commonly seen in neonatology were also included. These hospitals are important as they help in unclogging first and second category hospitals. These include:

- Bonassama District hospital (BDH) comprising 2 incubators, 8 cradles and 2 pediatricians;

- Nylon District hospital (NDH) with 2 incubators, 7 cradles and 2 pediatricians;

- Deido District hospital (DDH) having 4 incubators, 11 cradles and 2 pediatricians including 1 neonatologist.

\subsection{Study Population}

The study was focused on newborns transferred and admitted at neonatology wards of the above mentioned hospitals. We excluded newborns not transferred during the investigation, deceased during transport and those whose parents refused to take part in the study. Newborns were selected randomly and enrolled consecutively to avoid selection and information bias. The Minimum sample size of 200 newborns was required for the study based on Lorentz's formula by using a PT prevalence of $15.4 \%$ reported earlier [17], $n=Z^{2} \times p \times(1-p) / d^{2}$, where $\mathrm{n}=$ the required sample size, $\mathrm{Z}=$ statistic for the desired confidence level ( $\mathrm{Z}=1.96$ for $95 \%$ confidence level), $\mathrm{p}=$ assumed $\mathrm{PT}$ prevalence, and $\mathrm{d}=\mathrm{ac}-$ cepted margin of error (5\%).

\subsection{Data Collection}

Authorization and Ethical clearance were issued respectively by the manager of the health facility and ethical committee of the University of Douala. Thereafter, research project was submitted to caregiving staff. Eligible newborns were identified based on reviewing of admission forms and then informed consent was obtained from parents. Medical records of the included babies were scrutinized. Parents were asked on transport conditions and itinerary before admission at HF. Clinical examination of newborns was made on admission by a medical 
doctor to obtain data including: reason of transfer, temperature and respiratory distress signs. Whether perinatal network was used for PT was also sought. A summary of data collected for each newborn is presented in Table 1.

\subsection{Perinatal Network in Douala}

This network was created in December 2016 in the town of Douala. It comprises of 121 members including 2 administrators whose activities are voluntary. Members dedicated in management of mothers and newborns are recruited in public, private and confessional HFs. Communications are made day and night through the WhatsApp social media and thus each member is requested to own android phone and internet connection. This network lacks a coordination central unit and does not own proper transport means that can facilitate PT. The network aims at 1) giving information on availability of places at HF, 2) ensuring communication between HFs during PT, and 3) sharing helpful information for neonatal and maternal health.

\subsection{Operational Definitions}

- Medicalized transport: Newborn is accompanied with a caregiver and transported using an ambulance.

- Non-medicalized transport: utilization of taxi, motorcycles or personal vehicle to transport newborns even a caregiver is present.

- Initial contact: Notification of the HF through direct phone call or perinatal

Table 1. Variables collected in the study.

\begin{tabular}{|c|c|c|}
\hline Data & Types of variables & Sources \\
\hline Perinatal data & $\begin{array}{l}\text { - Age } \\
\text { - Gender } \\
\text { - Gestational age } \\
\text { - Route of delivery } \\
\text { - Adaptation to birth } \\
\text { - Birthweight }\end{array}$ & Medical records \\
\hline Transfer data & $\begin{array}{l}\text { - Reasons of transfer } \\
\text { - Transfer conditions } \\
\text { - Utilization of perinatal network }\end{array}$ & $\begin{array}{l}\text { Medical records, declaration } \\
\text { of parent, declaration of } \\
\text { medical staff }\end{array}$ \\
\hline $\begin{array}{l}\text { Clinical data on } \\
\text { admission }\end{array}$ & $\begin{array}{l}\text { - Reasons of transfer } \\
\text { - Temperature } \\
\text { - Respiratory distress }\end{array}$ & Medical records \\
\hline Outcome data & $\begin{array}{l}\text { - Recovery } \\
\text { - Discharge against medical advice } \\
\text { - Death and mortality rate } \\
\text { - Counter-reference }\end{array}$ & Medical records \\
\hline
\end{tabular}


network for requirement of a PT.

- Transferred/Referred: The newborn is transferred from one HF to another one.

- Therapeutic itinerary: Number of HF attended after initiating PT and before admission for hospitalization.

\subsection{Ethical Approval}

Authorizations were obtained from ethical committees of each HF. In addition, ethical clearance was issued by the institutional review board of the University of Douala $\left(\mathrm{N}^{\circ}\right.$ 2664). Data were collected in accordance with standards of medical research in Cameroon.

\subsection{Statistical Analysis}

Data were keyed and analyzed using the Epi Info 7 software. Qualitative variables were presented as percentage while quantitative variables were summarized as mean \pm standard deviation (SD). Pearson's independence chi-square test was used to compare percentages. Mean were compared using unpaired test. The risk of death among transferred newborns was determined by computing relative risk (RR), odds ratio (OR) along with confidence interval at 95\% (95\% CI) and probability value. Level of statistical significance was set at $p$-value $<0.05$.

\section{Results}

\subsection{Study Population}

Out of the 1159 newborns admitted at the neonatology wards of study sites, 234 (20.2\%) were transferred and thus included in the study (Figure 1).

\subsection{Sociodemographic and Perinatal Characteristics}

At the time of transfer, 137 (59\%), 68 (29\%) and 29 (12\%) of newborns were

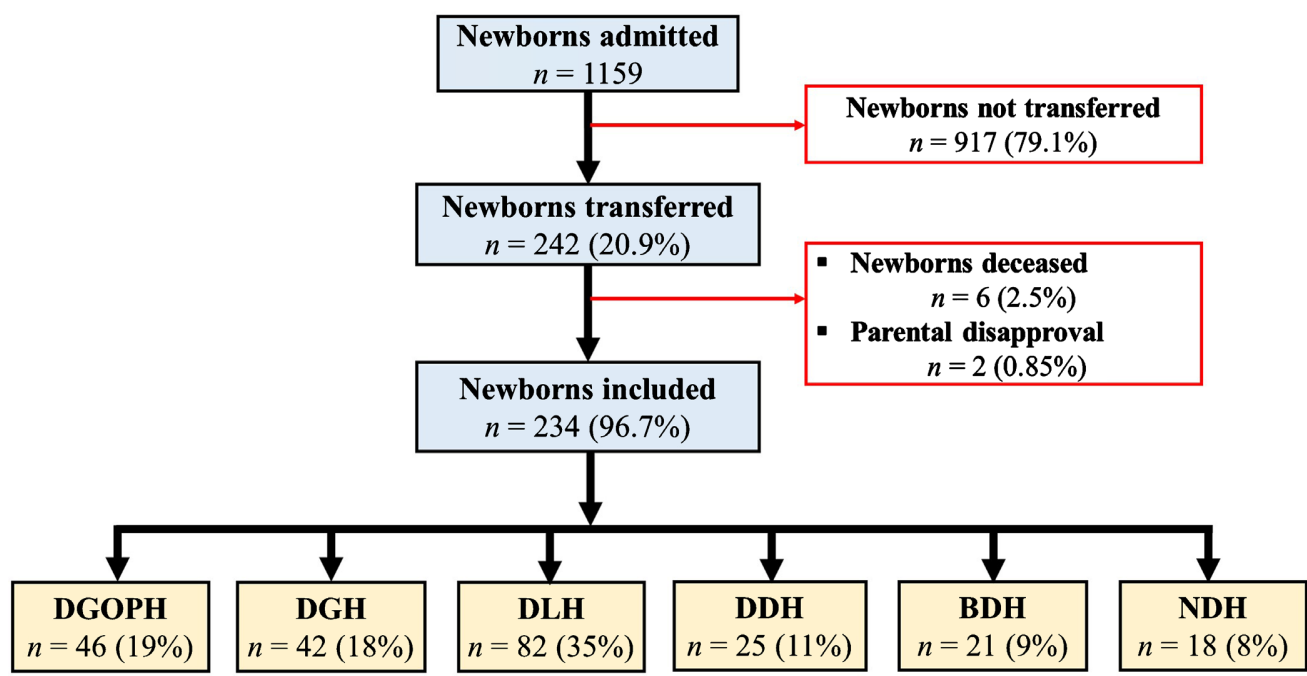

Figure 1. Flow diagram depicting the inclusion of newborns. 
aged 1 - 7 days, <24 hours and $>8$ hours, respectively. Males accounted for $57 \%$ of the transferred babies, giving a male-to-female ratio of 1.3. Pre-term births represented $17 \%$ of all births while $39 \%$ and $26 \%$ of the transferred babies had APGAR score $<7$ and birthweight comprised between 1500 and $2400 \mathrm{~g}$ (Figure 2).

\subsection{Prevalence and Reasons of Postnatal Transfer}

The overall prevalence of PT was $20.2 \%$ (95\% CI $17.9 \%-22.6 \%$ ) across all the study sites. A total of 11 pathologies and disorders were causes of PT with mainly neonatal infection $(26.5 \%, n=62)$, prematurity $(23.5 \%, n=55)$ and respiratory distress $(15.1 \%, n=36)$ (Figure 3 ).

\subsection{Conditions of the Transfer and Clinical Status on Admission}

Table 2 presents conditions of the PT and clinical evaluation of transferred newborns on admission at the study HFs. More than $90 \%$ of the transferred newborns were accompanied by their parents. About $78.63 \%$ of the newborns

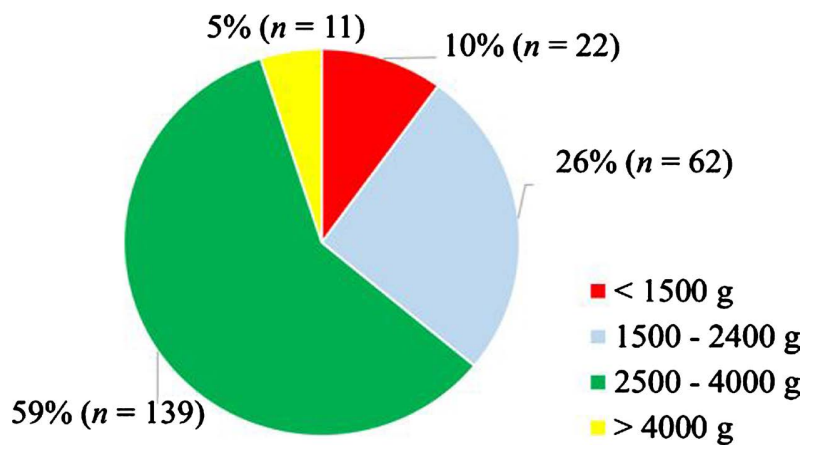

Figure 2. Birthweight distribution of the transferred newborns.

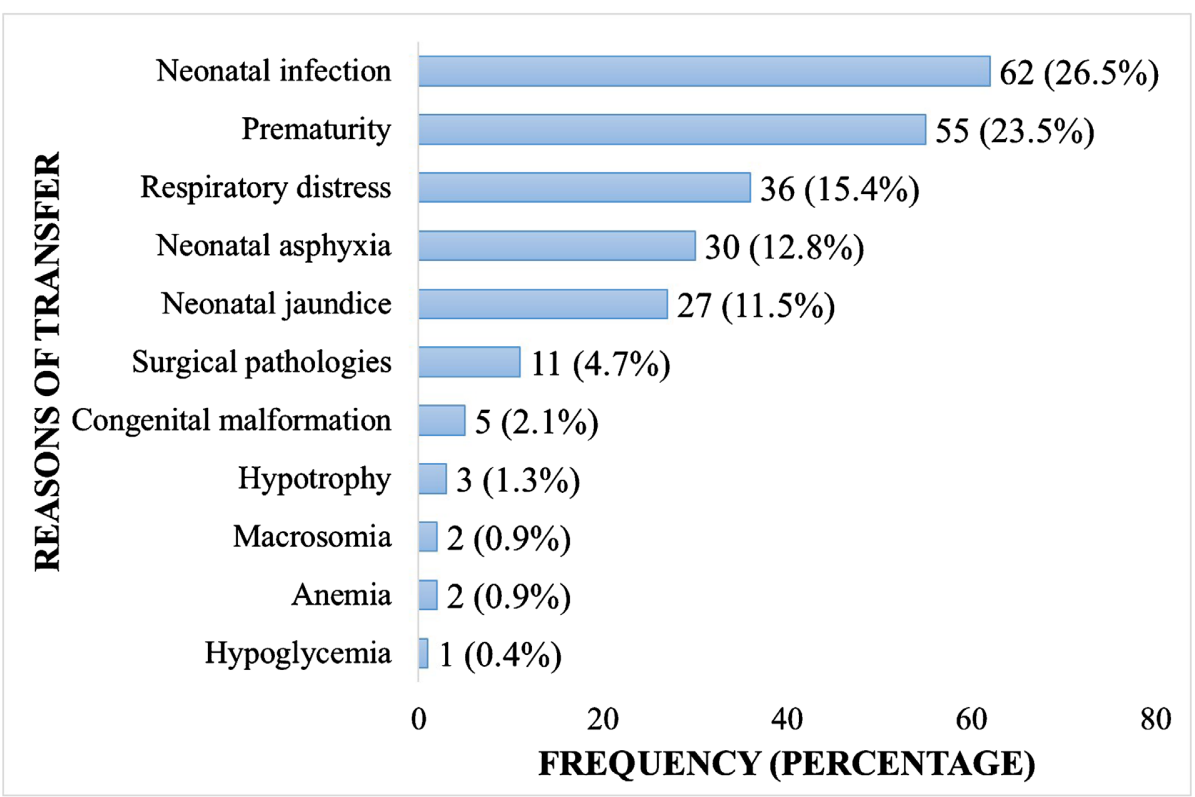

Figure 3. Reasons of postnatal transfer. 
Table 2. Characteristics of transport and clinical details of the transferred newborns.

\begin{tabular}{|c|c|c|c|}
\hline Variables & Categories & $n$ & $\%$ \\
\hline \multirow[t]{2}{*}{ Resuscitation before transfer } & Yes & 63 & 26.9 \\
\hline & No & 171 & 73.1 \\
\hline \multirow[t]{2}{*}{ Initial contact before transfer } & Yes & 50 & 21.4 \\
\hline & No & 184 & 78.6 \\
\hline \multirow[t]{2}{*}{ Availability of transfer form } & Yes & 131 & 56.0 \\
\hline & No & 103 & 44.0 \\
\hline \multirow[t]{2}{*}{ Accompanier present during transfer } & Medical staff & 18 & 7.7 \\
\hline & Parents & 216 & 92.3 \\
\hline \multirow[t]{3}{*}{ Detour to another facility before admission } & 0 & 188 & 80.3 \\
\hline & 1 & 39 & 16.7 \\
\hline & $\geq 2$ & 7 & 3.0 \\
\hline \multirow{2}{*}{ Communication during transfer } & Yes & 50 & 21.4 \\
\hline & No & 184 & 78.6 \\
\hline \multirow[t]{2}{*}{ Transport mode } & Medicalized & 6 & 2.6 \\
\hline & Non-medicalized & 228 & 97.4 \\
\hline \multirow[t]{2}{*}{ Respiratory distress } & Yes & 87 & 37.2 \\
\hline & No & 147 & 62.8 \\
\hline \multirow[t]{3}{*}{ Temperature on admission } & Normothermia & 104 & 44.4 \\
\hline & Hypothermia & 70 & 29.9 \\
\hline & Hyperthermia & 29 & 29.9 \\
\hline
\end{tabular}

were not announced before transfer to HFs. About $16.7 \%$ of the newborns overcome a detour to another health facility before admission at the study sites. Transport was not medicalized in $97.4 \%$ of the babies, and $29.9 \%$ were suffering from hypothermia on admission. More than one third (37.2\%) of babies were suffering from respiratory distress on admission.

\subsection{Utilization of the Perinatal Network}

The perinatal network was lowly (2\%) used and concerned DGOPH and DGH with rates of $8.7 \%$ and $2.3 \%$, respectively (Table 3 ). The perinatal network was not used at the DLH, BDH, DDH and NDH facilities.

\subsection{Outcome, Mortality Rate and Mortality Risk}

Of the 234 newborns referred to the study HFs, 46 (20\%) are deceased. Evolution of these babies was depicted in Figure 4. Based on logistic regression analysis, the odds of mortality were 2.33 times higher in transferred newborns compared to their counterparts who didn't need transfer (95\% CI $1.58-3.11, p<0.0001)$ 
Table 3. Utilization frequency of the perinatal networks by study sites.

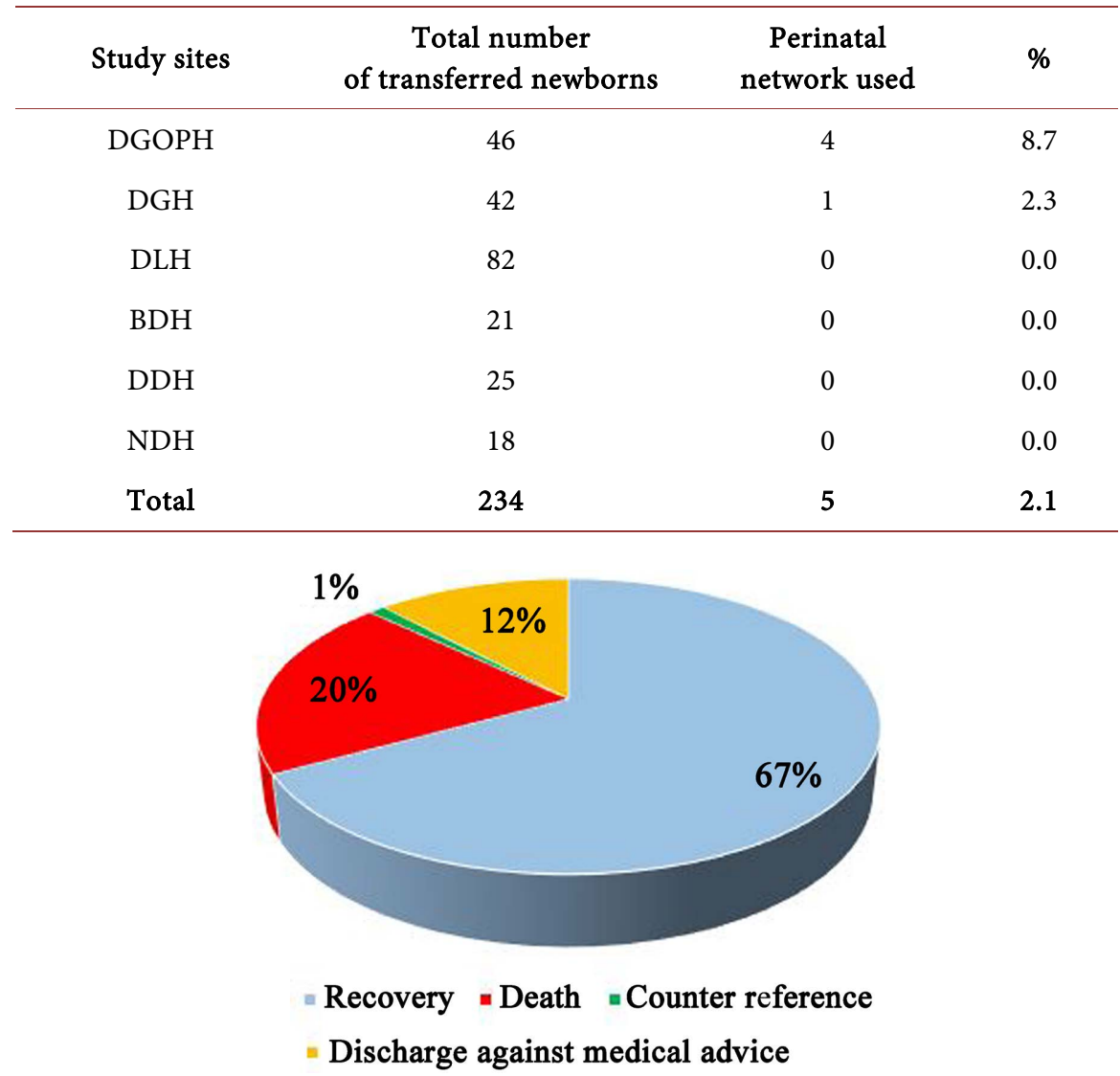

Figure 4. Outcomes of the transferred newborns at study sites.

Table 4. Mortality risk in transferred newborns.

\begin{tabular}{ccccccc}
\hline $\begin{array}{c}\text { Transferred } \\
\text { newborn }\end{array}$ & $\mathbf{N}$ & $\begin{array}{c}\text { Deaths } \\
\boldsymbol{n}(\%)\end{array}$ & RR (95\% CI) & $\boldsymbol{p}$-value & OR (95\% CI) & $p$-value \\
\hline No & 917 & $87(8.49 \%)$ & 1 & & 1 & \\
Yes & 234 & $46(19.6 \%)$ & $2.07(1.57-3.06)$ & $<0.0001^{*} 2.33(1.58-3.44)$ & $<0.0001^{*}$
\end{tabular}

RR: Relative risk, OR: Odds ratio, 95\% CI: Confidence interval at 95\%. ${ }^{\star}$ Statistically significant at $p$-value less than 0.05 .

(Table 4). Similar results were found based on computation of the RR for mortality $(\mathrm{RR}=2.07, p<0.0001)$.

\section{Discussion}

\subsection{Prevalence of Neonatal Transfer}

The present study aimed at describing PT at selected Government hospitals in Douala, Cameroon. Prevalence of PT was $20.2 \%$ and this is consistent with that reported earlier by Katsuya et al. in Japan (20.5\%) and Omoigberale et al. in Benin (15.4\%) [9] [17]. In contrast, higher prevalence values were reported in $\mathrm{Ni}$ geria (50.9\%) and Mali (71\%) [18] [19]. The last one has been conducted in the 
reference neonatology center in the town of Bamako (Mali), and this could explain the discrepancy between their results and ours.

\subsection{Gender Distribution of the Transferred Newborns}

More than half of transferred newborns were males. Faye and colleagues also reported a predominance of males among transferred babies in Senegal [13]. Newborns aged $<24$ hours accounted for $29 \%$ of transfers, and this finding is lower than that reported by Salomé et al. in Jamaica (62\%) and Daussac et al. in France (50\%) [20] [21]. Late transfer in our context is the result of financial constraints that hinder initiation and coordination of PT. Additional reasons could include instability of newborns, absence of transport means and/or adequate HF. Again, these factors likely increase the risk of neonatal death, and this study we found $2 \%$ of newborns were arrived dead at the study HFs.

\subsection{Reasons of the Transfer}

Prematurity was found in $36 \%$ of transferred newborns and this is not in line with value (24\%) reported in 2018 by Chioukh et al. in Tunisia [11]. In utero transfer is indicated for pre-term births when management of babies is not possible at birth place [22]. Furthermore, $24 \%$ of transferred newborns were born by caesarian. This point is crucial as neonatal risks should be carefully evaluated before making decisions for caesarian. To be noted, $37 \%$ of newborns had APGAR score $<7$, and this poor adaption of newborns elicits a higher risk of death [23].

The predominance of neonatal infection among reasons for PT was also reported in Senegal where authors found neonatal infection was responsible for $35 \%$ of all PT causes. Neonatal infection is the main pathology encountered in clinical practice at neonatology wards, and the WHO estimated that it accounts for $20 \%$ of global neonatal mortality [24]. Prematurity (24\%) and respiratory distress (15\%) were the second and third reasons for PT in the study, and this is consistent with result found by Traoré et al. (2010) in Mali (29\% and 14\%), but lower than that found by Salomé et al. (2017) in Jamaica who reported $>50 \%$ of PT due to prematurity and respiratory distress [25] [26]. Jaundice was also a cause of PT with $12 \%$ and this is higher than value found in Nigeria (9\%) and Jamaica (2\%) [19] [20]. The lack of phototherapy facility could likely explain this high value in several low categories hospitals in our setting.

\subsection{Utilization of the Perinatal Network}

Only 5 of the 234 newborns were transferred through perinatal network, giving a utilization percentage of $2 \%$. This finding is particularly worrisome as compared with other settings such as Japan where a study reported a utilization percentage of $62 \%$ [9]. In this country, perinatal network disposes a coordination center in each town which first receives calls from facilities requiring PT and then provides human resource and equipment for PT. Regarding transfer conditions, 
health facilities receiving transferred newborns had been contacted for $21 \%$ of them. This is consistent with that found in Senegal (27\%) [12]. Whenever PT is decided, it is crucial to inform HF that supposed to receive newborns for a better management [27]. Transfer forms were missing for $44 \%$ of newborns. Such forms are important for better coordination between HFs and its utilization is recommended as a part of health norms and standards of the Ministry of Public Health in Cameroon [28].

\subsection{Itinerary and Conditions of Neonatal Transfer}

On analysis of itinerary, we noted that detours were made by $17 \%$ of newborns before their admission at the study facilities. Previous studies reported rate of $56 \%$ in the town of Yaoundé, Cameroon [14]. Newborns are managed by medical staff during transport in $92 \%$ of cases which is contrary to national guidelines [28]. Transport was medicalized in $3 \%$ of newborns included in the study and this is consistent with report in The Democratic Republic of Congo, but contrasting with higher values found in Senegal (30\%) and Japan (96\%) [9] [12] [13]. Transport of newborns to adequate emergency unit necessitates surveillance and high quality care to limit risk of death [9].

To be noted, hypothermia was found in $30 \%$ of newborns admitted at the health facilities. This supports result of Faye and colleagues who reported $34 \%$ in Senegalese babies [12]. Transport conditions could likely explain the presence of hypothermia. Indeed, most of transports were non-medicalized and done through public means especially taxi. This fact was also found by Faye and colleagues [12]. Such inadequate transport means could explain why respiratory distress was found in more than one-third of the newborns at their admission, thereby suggesting that these transports could be a cause of respiratory distress in them.

\subsection{Mortality among the Newborns}

Mortality rate was $19.6 \%$ in this study. Other studies found values of $20.5 \%$ in Cameroon, 22.3\% in Senegal and 8.4\% in Tunisia [11] [12] [14]. Mortality rate remained unchanged even after implementation of the perinatal network which was lowly used as above discussed. In addition, transport conditions were similar to those seen before the implementation of the network (i.e., non-medicalized transport, detour before admission and hypothermia on admission) [29]. The risk of death was doubled in transferred newborns compared to their non-transferred counterparts. This could explain severity of the PT-driving pathology as well as complication of the pathology due to poor transport conditions.

\subsection{Limitations of the Study}

Data were collected from Government HFs and this constitutes the main limitation of the study. However, we conducted the study in the HFs receiving the large proportion of newborns referred in Douala, thereby outlining findings re- 
ported here are representative of the global scenario in Douala.

\section{Recommendations}

A set of key recommendations may be given based on the findings of the present study:

- The newborns were arrived at the HF with respiratory distress, and this should the need for information, education and communication campaigns, through seminars for instance, of the medical staff on in utero transfer;

- The PT network was largely underused by the HF included in the study. It is utmost importance of updating members of the utilization of this network along with creation of a center for its coordination. Again, a better communication between both low- and high quality care HFs is crucial in order to improve the chances of survival of newborns when decision for transfer is made;

- Finally, the Government of Cameroon should be allocated funds and transport means such as ambulances for improving the utilization of the postnatal network

\section{Conclusion}

This study outlined that newborns were transferred at late stage and main reasons of PT were neonatal infection, prematurity and respiratory distress. It also pinpointed the absence of medicalized transport in 9 of 10 newborns, the absence/lack of transfer form, the absence of notification of the HF receiving transferred newborns and the low utilization of the perinatal network. Based on these findings, it should be important to reduce neonatal mortality through sensitization of medical staff on in utero transfer, updating of the members of the perinatal network and creation of a center for coordination of this network.

\section{Acknowledgments}

The authors are grateful to medical staff of Neonatology ward of the different health facilities (DGOPH, DGH, DLH, BDH, DDH and NDH) where the study was conducted. We are also thankful parents of the newborns who gave their consent for inclusion of their newborns.

\section{Authors' Contribution}

- Conception and design: Daniele Kedy Koum, Monique Carole Magnibou, Calixte Ida Penda.

- Acquisition of data: Monique Carole Magnibou, Diomede Noukeu Njinkui, Daniele Kedy Koum.

- Analysis and interpretation: Daniele Kedy Koum, Loick Pradel Kojom Foko, Rhita Mbono.

- Drafting/Revising the manuscript: Daniele Kedy Koum, Diomede Noukeu Njinkui, Loick Pradel Kojom Foko, Charlotte Eposse, Patricia Epée Eboum- 
bou, Calixte Ida Penda.

- Final approval of the version: all the authors.

- Agreement to be accountable for all aspects of the work: Daniele Kedy Koum, Calixte Ida Penda.

All the authors of the manuscript have read and agreed to its content and are accountable for all aspects of the accuracy and integrity of the manuscript.

\section{Conflicts of Interest}

The authors declare no conflicts of interest regarding the publication of this paper.

\section{References}

[1] Organisation Mondiale de la Santé. Nourrisson et nouveau-né. https://www.who.int/topics/.infant-newborn/fr

[2] Fayol, L., Maillotte, A.M., Cagnat, J. and Marcot, M. (2017) Orientation Des Nouveau-nés Malades. Réseau périnatal méditerranée, 1, 1-19. (In French)

https://www.reseauperinatmed.fr

[3] Baleine, J.F., Fournier-Favre, P. and Fabre, A. (2016) La spécificité du transport néonatal. Soins Pédiatrie/ Puériculture, 37, 25-29. (In French) https://doi.org/10.1016/j.spp.2016.07.005

[4] Rouabah, C. and Trabeisi, L. (2017) Transfert néonatal. Réseau Périnatal Lorrain. (In French) https://www.sciencedirect.com

[5] Organisation Mondiale de la Santé. Prise en charge des maladies du nouveau-né et des éventuelles complications. (In French)

https://www.who.int/maternal-chid-adolescent/topics/Newborn/management-illnes s-complications/fr

[6] Dugnat, M. (2012) Réseaux en périnatalité: les outils pratiques d'une prévention universelle prévenante? Définition critiques et propositions. Spirale, 1, 139-162. (In French) https://doi.org/10.3917/spi.061.0139

[7] Circulaire $\mathrm{n}^{\circ} \mathrm{DHO} / 01 / 03 / 2006 / 151$ de 2006 relative au cahier des charges national des réseaux de santé en périnatalité. NOR: SANH0630126C. (In French)

[8] Whyte, H.E. and Jefferies, A.L. (2015) Le transport interhospitalier des nouveau-nés gravement malades. Paediatrics \& Child Health, 20, 270-275. (In French)

[9] Hirata, K. (2019) Current Status of Neonatal Transfer in Osaka \& Japan. Osaka Women's and Children's Hospital. 59 p. https.//chrc.nhri.org.tw

[10] Jourdain, G., Lodé, N. and Chabernaud, J.L. (2019) Transport pédiatrique médicalisé en France en 2018. Journal de Pédiatrie et Puériculture, 32, 12-19. (In French) https://doi.org/10.1016/j.jpp.2018.10.005

[11] Chioukh, F.Z., Ben, A.K., Monastiri, K., Kbaier, H., Blibech, S., Douagi, M., Ben Hlel, K., Ben Hamouda, H., Soua, H., Bouraoui, A., Régaieg, R., Gargouri, A., Ksibi, I., Kacem, S., Mahdhaoui, N., Ayech, H. and Sboui, H. (2018) Transported Neonates in Tunisia. La Tunisie Médicale, 96, 865-868.

[12] Faye, P.M., Dieng, Y.J., Diagne-Guèye, N.R., Guèye, M., Bâ, A., Seck, M.A., Fattah, M., Sow, N.F., Thiongane, A., Basse, I., Fall, A.L., Diouf, S., Ndiaye, O., Sy-Signaté, H. and Sarr, M. (2016) Problématique des transferts néonatals dans la région de Dakar (Sénégal). Revue de Médecine Périnatale, 8, 94-102. (In French) https://doi.org/10.1007/s12611-016-0353-4 
[13] Katamea, T., Mukuku, O., Kamona, L., Mukelenge, K., Mbula, O., Baledi, L., Nntambwe, E., Mulangu Mutombo, A., Okitotsho Wembonyama, S. and Luboya, O.N. (2014) Mortality Risk Factors in Newborns Transferred to the Neonatal Unit of the Hospital Jason Sendwe Lubumbashi, DR Congo. The Pan African Medical Journal, 19, 169. (In French) https://doi.org/10.11604/pamj.2014.19.169.4018

[14] Nlend, N.A.E., Zeudja, C. and Nsoa L. (2016) Transfer and Transport of Newborn Babies in Vital Distress in Yaoundé, Cameroon: Situational Analysis Conducted in a Reference Hospital. The Pan African Medical Journal, 25, 214. (In French)

[15] Adidja, A., Nansseu, J.R., Mah, E.M., Meguejio Vougmo, C., Moluh Moluh, S. and Mbu, R. (2017) Use of a Social Media Network to Reduce Early Neonatal Mortality: A Preliminary Report from a Quality Improvement Project in Yaoundé, Cameroon. Maternal Health, Neonatology and Perinatology, 3, 26. (In French) https://doi.org/10.1186/s40748-017-0064-y

[16] Stratégie Spatiales (2019) Analyse géographique de la couverture sanitaire au Cameroun; Répartition des formations sanitaires et de la charge du personnel de santé. $\mathrm{N}^{\circ} 2$. (In French)

https://www.geostrategies.net/produit/strategies-spatiales-n2-mars-avril

[17] Omoigberale, A.I., Sadoh, W.E. and Nwaneri, D.U. (2010) A 4 Year Review of Neonatal Outcome at the University of Benin Teaching Hospital, Benin City. Nigerian Journal of Clinical Practices, 13, 321-325.

[18] Dicko TF, Sylla M, Diakité AA,Soilihin A., N’Diaye, M.D., Togo, B., Diakité, F.L., Konaté, D., Traoré, B., Sidibé, T. and Keita, M.M. (2010) Problems of Neonatal Transfer to the Pediatric Service of the CHU Gabriel Touré of Bamako. Mali Medical, 25, 25-28.

[19] Mukhtar-Yola, M. and Iliyasu, Z. (2007) A Review of Neonatal Morbidity and Mortality in Aminu Kano Teaching Hospital, Northern Nigeria. Tropical Doctor, 37, 130-132. https://doi.org/10.1258/004947507781524683

[20] Salomé, H. and Trotman, H. (2017) Challenges in Neonatal Transport in Jamaica: A Resource-Limited Setting. Journal of Tropical Pediatrics, 63, 307-313.

[21] Daussac, E., Leslie, A., Roth-Kleiner, M., Zwissig, M., Aufieri, R., Gente, M. and Jourdain, G. (2018) Le transfert néonatal par un SMUR pédiatrique, de la salle de naissance à la réanimation, en France... et ailleurs. Revue de Médecine Périnatale, 10, 50-58. (In French) https://doi.org/10.3166/rmp-2018-0006

[22] Schwartz, H.P., Bigham, M.T., Schoettker, P.J., Meyer, K., Ttrautman, M.S., Insoft, R.M. and American Academy of Pediatrics Section on Trasport Medicine (2015) Quality Metrics in Neonatal and Pediatric Critical Care Transport: A National Delphi Project. Pediatric Critical Care Medicine, 16, 711-717. https://doi.org/10.1097/PCC.0000000000000477

[23] Cnattingius, S., Norman, M., Granath, F., Peterson, G., Stephansson, O. and Frisell, T. (2017) Apgar Score Components at 5 Minutes: Risks and Prediction of Neonatal Mortality. Paediatric and Perinatal Epidemiology, 31, 328-337. https://doi.org/10.1111/ppe.12360

[24] Organisation Mondiale de la Santé. Prise en charge d'une infection bactérienne potentiellement grave chez le jeune nourrisson âgé de 0 à 59 jours lorsqu'un transfert vers une structure hospitalière est impossible. (In French)

https://apps.who.int/iris/bitstream/handle

[25] Shi, W.W., Smith, G., Yang, Q. and Walker, M. (2004) Epidemiology of Preterm Birth and Neonatal Outcome. Seminar in Fetal and Neonatal Medicine, 9, 429-435. https://doi.org/10.1016/j.siny.2004.04.002 
[26] Guibert, J. (2015) Réanimation néonatale: Processus décisionnel et "euthanasie d'exception”. Espace éthique Ile-de-France. https://www.espace-ethique.org

[27] Bose, A. (2017) Transfer of the Sick Neonate: What Is Needed? Journal of Tropical Pediatrics, 63, 165-166. https://doi.org/10.1093/tropej/fmx021

[28] Ministère de la Santé Publique (201) Normes-Standards-en-SR-PF-au-Cameroun. (In French) https://www.prb.org

[29] Chabernaud, J.-L., Ayachi, A., Lodé, N., Lelong-Tissier, M., Diependaele, J. and Menthonnex, E. (2010) Histoire du transport néonatal: Progrès dans l'organisation au cours des 30 dernières années. Revue de Médecine Périnatale, 2, 63-71. https://doi.org/10.1007/s12611-010-0067-7

$\begin{array}{ll}\text { Abbreviations } \\ \text { BDH } & \text { Bonassama District Hospital } \\ \text { DDH } & \text { Deido District Hospital } \\ \text { DGH } & \text { Douala General Hospital } \\ \text { DGOPH } & \text { Douala Gyneco-Obstetrics and Pediatrics hospital } \\ \text { DLH } & \text { Douala Laquintinie Hospital } \\ \text { NDH } & \text { Nylon District Hospital } \\ \text { CI } & \text { Confidence Interval } \\ \text { HF } & \text { Health Facility } \\ \text { OR } & \text { Odds Ratio } \\ \text { PT } & \text { Postnatal transfer } \\ \text { RR } & \text { Relative Risk } \\ \text { WHO } & \text { World Health Organization }\end{array}$

